\title{
Erratum to: Mechanical ion gate for electrospray-ionization ion-mobility spectrometry
}

\author{
Li Zhou • David C. Collins • Edgar D. Lee •
}

Alan L. Rockwood • Milton L. Lee

Published online: 14 August 2010

(C) Springer-Verlag 2010

\section{Erratum to: Anal Bioanal Chem}

DOI 10.1007/s00216-007-1177-3

\begin{abstract}
Alan L. Rockwood, ARUP Institute for Clinical and Experimental Pathology, 500 Chipeta Way, Salt Lake City, Utah 84108, USA, was inadvertently left out of the coauthor list of the original publication. He suggested the idea for gating the ion signal with a mechanical chopper and participated in the design of the ion mobility spectrometer.

The correct sequence of authors of this contribution is:

Li Zhou, David C. Collins, Edgar D. Lee, Alan L. Rockwood and Milton L. Lee.
\end{abstract}

The online version of the original article can be found at http://dx.doi. org/10.1007/s00216-007-1177-3.

L. Zhou $\cdot$ E. D. Lee $\cdot$ M. L. Lee $(\bowtie)$

Department of Chemistry and Biochemistry,

Brigham Young University,

Provo, UT 84602-5700, USA

e-mail: milton_lee@byu.edu

D. C. Collins

Department of Chemistry, Brigham Young University-Idaho,

Rexburg, ID 83460, USA

A. L. Rockwood

ARUP Institute for Clinical and Experimental Pathology,

500 Chipeta Way,

Salt Lake City, UT 84108, USA 